\title{
Global environmental monitoring from space
}

\author{
Kohei $\mathrm{Arai}^{{ }^{*}}$ \\ ${ }^{1}$ Department of Information Science, Saga University, Saga City, Japan
}

\begin{abstract}
. we are facing global environmental issues such as global warming, ozone depletion, deforestation, air pollution, ocean pollution, desertification, etc. Homeostasis among geosphere, atmosphere, cryosphere, hydrosphere, biosphere has to be maintained. In order for Global Sustainability, global environmental monitoring from space is needed. The monitoring system does work for not only global environmental monitoring, but also disaster mitigation such as Sulawesi Big Earthquake and Tsunami which was occurred on 28 September 2018. Other than environmental monitoring from space, modeling and simulation, big data analysis, Artificial intelligence are also needed.
\end{abstract}

\section{Introduction}

We are facing global environmental issues such as global warming, ozone depletion, deforestation, air pollution, ocean pollution, desertification, etc. Homeostasis among geosphere, atmosphere, cryosphere, hydrosphere, biosphere has to be maintained. In order for Global Sustainability, global environmental monitoring from space is needed. The monitoring system does work for not only global environmental monitoring, but also disaster mitigation such as Sulawesi Big Earthquake and Tsunami which was occurred on 28 September 2018. Other than Environmental Monitoring from Space, Modeling and simulation, big data analysis, Artificial intelligence are also needed.

Land remote sensing and global environmental changes are overviewed [1]. Experiments on resampling of local unequally spaced Remote Sensing data and relative radiometric correction of linear array sensor data is proposed [2]. Japan's environmental observation satellite plans for the 1990's is introduced [3]. A review of current Earth observation data and information systems is well reported [4]. Observation of aerosol parameters at Saga using GOSAT product validation Lidar is well reported [5]. Big data platform for agricultural field monitoring and environmental monitoring is introduced [6].

In this paper, global environmental issues are introduced. Then, remote sensing satellites which allow global environment observation are described followed by big data of satellites data platform is overviewed. Examples of satellite observations for global environmental monitoring and disaster mitigation are described. Finally, the conclusion and some discussions are described.

*Corresponding author: arai@is.saga-u.ac.jp 


\section{Global issues}

\subsection{Global warming}

There are some issues related to global warming that have been faced by many countries on earth as follows: a) $\mathrm{CO}_{2}$ concentration before industrial revolution: $0.028 \%$, b) in year 2018: $0.04 \%$, air temperature raised with 0.74 degree within 100 years, c) 0.8 to 3.5 degree of global warming is anticipated at 2100 , d) Methane, Freon, halon, nitrogen oxides, e) Carbon stock: 170 Billion ton since industrial revolution, f) Carbon emissions: 27 Billion ton a year, g) Arctic and Antarctic sea ice shrinks and the late summer sea ice in the Arctic Ocean disappears by the latter half of the $21^{\text {st }}$ century, h) Extreme high temperature, heat wave, heavy rain frequency increases, i) Even if the $\mathrm{CO}_{2}$ concentration stabilizes at 720 ppm in 2100 , the sea level rises by $30-80 \mathrm{~cm}$ in 2300 only by thermal expansion.

Averaged air temperature of the earth is $15 \mathrm{~K}$ so that $33 \mathrm{~K}$ is the greenhouse effect of the earth. Contribution factors of atmospheric molecule are as follows: a) $\mathrm{CO}_{2}(0.028 \% \rightarrow$ $0.037 \%$, global warming contribution factor: 1), b) $\mathrm{CH}_{4}(700 \mathrm{ppb} \rightarrow 1720 \mathrm{ppb}, 21)$, c) $\mathrm{N}_{2} \mathrm{O}$ $(275 \mathrm{ppb} \rightarrow 312 \mathrm{ppb}, 310)$, d) CFC-11(0 $\rightarrow 268 \mathrm{ppt}, 3800)$, e) CFC-22(0 $\rightarrow 110 \mathrm{ppt}, 1500)$, f) $\mathrm{CF}_{4}(0 \rightarrow 72 \mathrm{ppt}, 6500)$.

Contribution of greenhouse gasses excluding $\mathrm{CO}_{2}$ is about half of that of $\mathrm{CO}_{2}$. In accordance with IPCC, averaged sea level is going down between 1990 to 2100 around 0.8 3.5 degree (1.4-5.8) or 9-88 cm. The fact says that increasing of Carbon dioxide may cause the following $\mathrm{CO}_{2}: 0.74$ degree/100 years. Fossil fuel releases Nitric acid aerosol (several weeks in the stratosphere).

\subsection{Global issues other than global warming}

Some other global issues other than global warming were detected as the impact of the following activities:

1) Deforestation. Forest damages due to acid rain are Denmark (61), Russia (59), Netherland (58), UK (56), Swiss (56), Germany (52). The number in the bracket denote percentage ratio of the damaged forest areas.

2) Ozone depression. The ozone depletion damages about half of ozone concentration arctic area. The ozone depletion ratio of Japan is approximately of $5 \%$ a year. The reaction can be defined as $\mathrm{O}_{3}+\mathrm{Cl}=\mathrm{O}_{2}+\mathrm{ClO}, \quad \mathrm{ClO}+\mathrm{O}=\mathrm{Cl}+\mathrm{O}_{2}$. Stratospheric ozone continues to be repeatedly destroyed by chlorine atoms. Polar cloud occurs in the summer of Antarctica, sunlight and cloud particles activate chlorine causing ozone depletion. The reaction can be written as follows: $\mathrm{CFCl}_{2} \rightarrow \mathrm{Cl}+\mathrm{Cl}+\mathrm{CF}, \mathrm{Cl}+\mathrm{O}_{3} \rightarrow \mathrm{ClO}+\mathrm{O}_{2}$ $\rightarrow \mathrm{ClO}+\mathrm{O} \rightarrow \mathrm{Cl}+\mathrm{O}_{2}$.

3) Desertification. Around $1 / 3$ of land area became desert already, desertification rate: areas of Kyushu $\left(44,512.60 \mathrm{~km}^{2}\right)$ and Shikoku $\left(18,297.78 \mathrm{~km}^{2}\right), 63,000 \mathrm{~km}^{2}$ a year. Approximately of $1 / 3$ of all land is dry or semi-arid. Climatic factors + artificial factors (overgrazing, overcultivation, excessive collection of firewood charcoal) $\rightarrow$ desertification of 3.5 billion hectares of agricultural land $\rightarrow 230$ million people affected, despite the United Nations Action Plan to Prevent Desertification in 1974. 
4) Deforestation. About 11.3 million ha has been damaged with a deforestation rate around a half of Honshu $\left(227,942.85 \mathrm{~km}^{2}\right), 120,000 \mathrm{~km}^{2}$ area a year.

5) The number of species is 10 million, and we lost 0.15 million of species already.

6) Air pollution. Stratospheric ozone has cooled the earth, while tropospheric ozone becomes global warming. In Europe the majority of air pollution is caused by sulfur dioxide, in America is due to NOx, and in Africa is caused by CO (not soluble in rain). Methane $\rightarrow$ Tax. Nitrogen oxides, hydrocarbons degenerate, tropospheric ozone is generated Global warming $\rightarrow$ Convection activity active $\rightarrow$ Lightning $\rightarrow$ NOx: 3.5 $\mathrm{kg} / \mathrm{m}^{2} / \mathrm{s}(1990) \rightarrow 5(2100)$.

7) Ocean pollution. Golf course, farm land. Pesticide Industrial waste disposal: PCB, plastic. Garbage incineration: dioxin. Agricultural land: insecticide. Factory: mercury, cadmium. Ship: oil slick.

8) The number of species. Scientifically identified: 150-16 million species (insects: 750,000 , plants: 250,000, crustaceans: 120,000, mammals: $7000(0.3 \%)$, food $\rightarrow$ about 30,000 species). In addition to this, there are 10 million species. Scientifically identified: Boreal: $6 \%$, temperate: 59\%, tropical: $35 \%$, Including unidentified, Boreal: $1-2 \%, 13-24 \%$ in temperate zone, $74-86 \%$ in tropical zone. Especially the tropics are $7 \%$ of the earth's surface, but only $40 \%$ species exists. The earth of the year 2000 AD has 10 million species $15 \%$ extinction by 2000 .

\section{Remote sensing satellites}

\subsection{Example of remote sensing satellite image}

There are four specific features of remote sensing satellites, namely extensibility, repetitive, long-term observation, and monitoring from space. Fig. 1 is an example of remote sensing satellite image acquired from Terra-1, Aqua-1 MODIS sensors. Animated typhoon 21 time series data observed over 2003/11/25-30 are shown in Fig. 1. One pass is 2,300 km, day one day 3-4 scenes, capturing the movement of the typhoon well. 


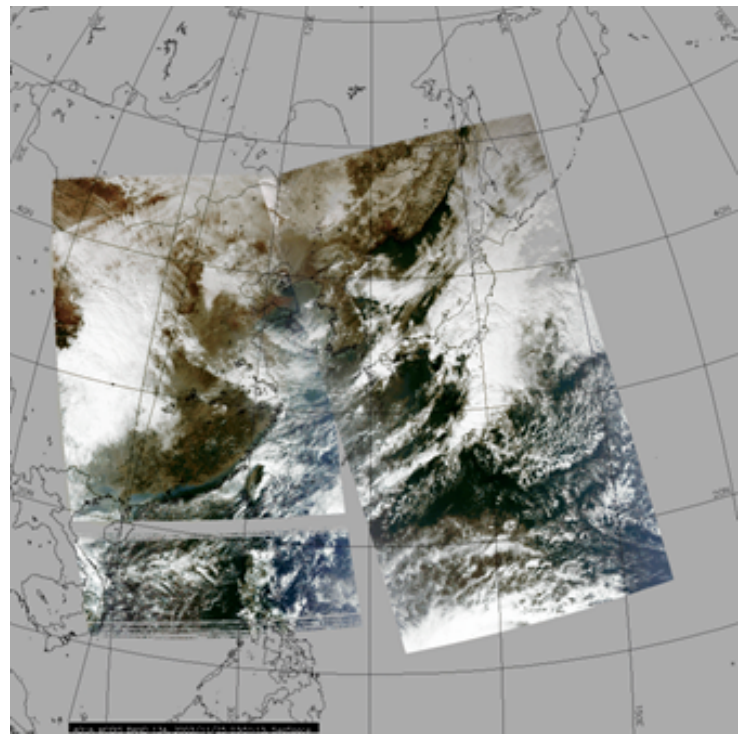

Fig. 1. Example of remote sensing satellite image.

\subsection{Examples of remote sensing satellite image applications}

Some examples of remote sensing satellite image application in determining, predicting and overcoming impacts of various climate change and geographical change phenomenons:

1) El Nino. The El Niño phenomenon off Peru can be observed from space. The seasurface temperature and its deviation from mean temperature can be derived. In November 2002, the deviation peaked at 2 or 3 degrees (red area) off Peru, which indicates the mature phase of the El Niño phenomenon. We can use this information to determine climate trends like temperature, amounts of rainfall, the number of typhoons, and the end of the rainy season.

2) Rainfall. The monthly rainfall of January 2004 and hourly rain rate can be estimated. Tropical areas and subtropical areas provide over two-thirds of all rainfall on Earth and play a vital role in the global water cycle. We can map the rainfall distribution and use this information for abnormal climate investigation and flood forecasting. This April 2003 satellite image shows yellow dust coming from the Asian continent over the Sea of Japan. We can see it lightly spread all over the Japan Sea. This image allows us to observe approaching yellow dust, which may help us improve aircraft security and safety.

3) Ozone Hole. A satellite image taken at the Antarctic Pole indicates an ozone hole. The lower left icon shows the biggest ozone hole (September 10,2000), and the lower right image indicates the second biggest ozone hole (September 24, 2003). The ozone hole is represented in violet or blue in the pictures. This information is useful for predicting harmful ultraviolet rays.

4) Sea Ice. A satellite image of sea ice in Arctic Pole, Antarctic Pole, and pack ice distribution in the Sea of Okhotsk allows us to see the current sea ice and pack ice distribution even under bad weather conditions of the winter sea. This information may help to improve the safety of ships in that area. 
5) Heat Wave. A satellite image represents unusually high temperatures in Europe during the summer of 2003. Red indicates land-surface temperatures that were higher in 2003 than in 2002. Using the satellite image we can estimate the distribution of land surface temperature and determine the influences of temperature and insolation on crops. This could help prevent damage from the cold.

6) Turbidity. A satellite image represents the red tide of Tokyo Bay in March 2003. The picture in the center indicates the turbidity distribution. The image on the right indicates clarity distribution. High turbidity areas and low clarity areas are caused by red tide. Using this information, we can plot the red tide distribution and more precisely control water purity.

7) Soil Moisture. Images represent estimated soil wetness on land surfaces during February 1998 and August 1998. A portion of images indicates little humidity, and the other shows much moisture. We can estimate soil wetness and use this data to select cultivation methods and grazing areas.

8) Geography. An image on the left indicates Maebashi-city area of 1999, and the picture on the right is a 1997 edition map of the same area. We can track landform changes to create and update maps so we can manage land utilization development. These images are simulation generated from envisioned examples of the utility of Advanced Land Observing Satellite (ALOS), which was launched in 2004.

\section{Saga University projects}

\subsection{Satellite data acquisition and processing system}

Saga University satellite data reception system is shown in Fig. 2.

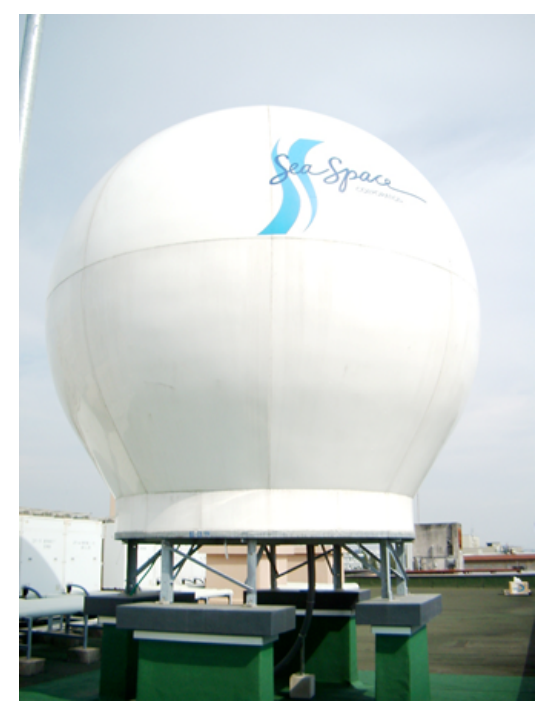

Fig. 2. Saga University satellite data reception system. 


\subsection{GOSAT Satellite System}

Saga ground based-FTS operation started from July 2011. Outlook of ground station is shown in Fig. 3.

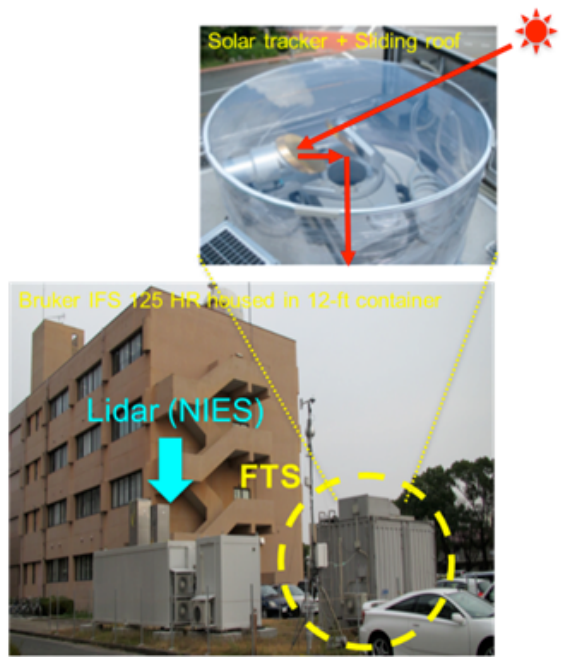

Fig. 3. GOSAT data verification site.

At the site, following data are acquired: 1) GOSAT targets at Saga every 3 days; 2) OCO-2 can target 2 days in 16-day revisit. Fig. 4 shows the trends of the total column carbon dioxide and methane.
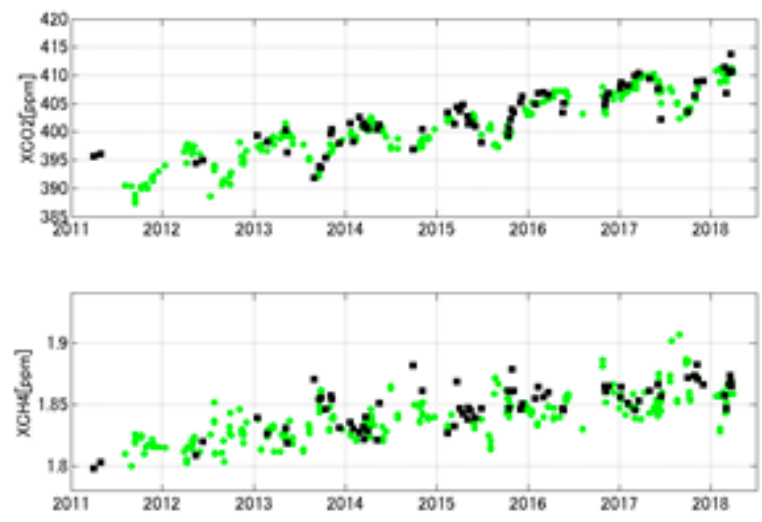

Fig. 4. Trends of the total column carbon dioxide and methane.

Other than the FTS data, the following data which are shown in Fig. 5 are acquired for the reference. 


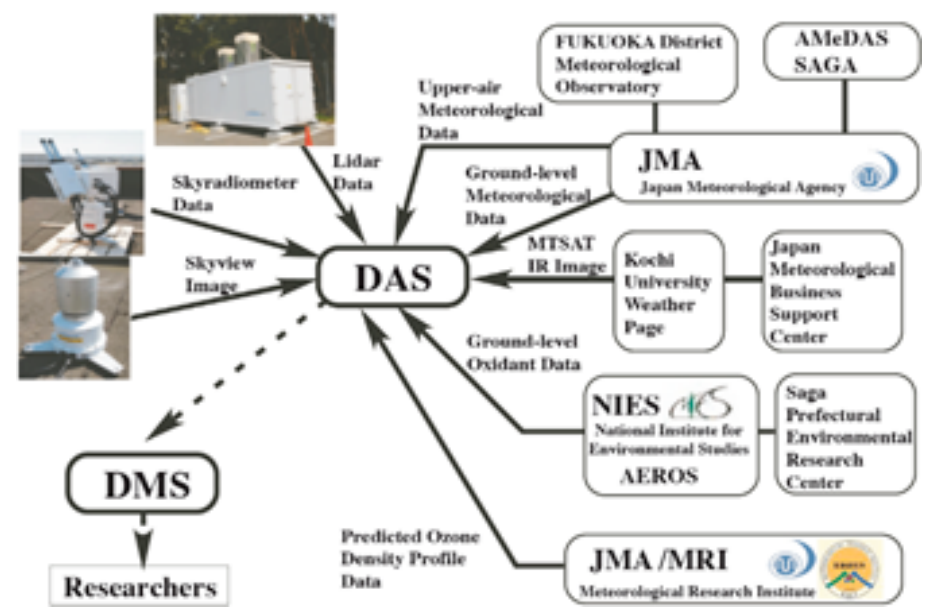

Fig. 5. All the acquired data at Saga University GOSAT verification site.

Fig. 6 shows an example of GOSAT verification site provided PM2.5 distribution in Kyushu, Japan. This PM2.5 distribution can be seen in worldwide basis.

\section{Other activities}

Practical applications of small satellites such as LAPAN A1(TUBSAT), A2 and A3 (LISAT) is also expanded. Saga University is contributing LAPAN-IPB satellite project in particular for vicarious calibration and image quality evaluations. Sulawesi Big Earthquake and Tsunami which was occurred on 28 September 2018. Saga University is still working on satellite data analysis for disaster relief and the creation of disaster recovery.

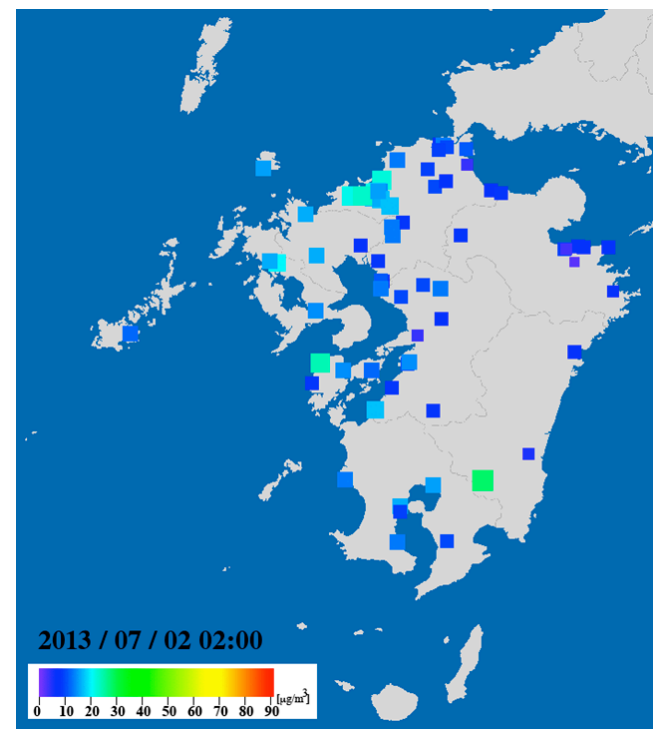

Fig. 6. Example of PM2.5 distribution.

\section{Conclusions}


Homeostasis among geosphere, atmosphere, cryosphere, hydrosphere, biosphere has to be maintained. In order for Global Sustainability, global environmental monitoring from space is needed. The monitoring system does work for not only global environmental monitoring, but also disaster mitigation such as Sulawesi Big Earthquake and Tsunami which was occurred on 28 September 2018. Other than Environmental Monitoring from Space, Modeling and simulation, Big data analysis, Artificial intelligence are also needed. As a result, it was found that the time required to eat one food was almost 30 seconds. For future work, Sulawesi Big Earthquake and Tsunami which was occurred on 28 September 2018. Saga University is still working on satellite data analysis for disaster relief and the creation of disaster recovery.

The author would like to thank Dr. Ari Sandhyavitri, M.Sc Dr. Muhammad Yusa, Mardan Fajri, Dr. Eng. Sigit Sutikno from Civil Engineering Department, University of Riau, Pekanbaru, Indonesia for their valuable cooperation of satellite data analysis.

\section{References}

1. K. Arai, K. Thome, A. Iwasaki, S. Beggar, Land Remote Sensing and Global Environmental Changes, Part-II, Sec. 5: ASTER VNIR and SWIR Radiometric Calibration and Atmospheric Correction (Springer, New York, 2010)

2. K. Tsuchiya, K. Arai, F. Kumura, K. Honma, S. Yamagata, Proc. of the $17^{\text {th }}$ International Symposium on Remote Sensing of Environment (1983)

3. T. Tanaka, K. Arai, Proc. of the IGARSS'89 (1989)

4. K. Arai, Proc. of the Expert Advisory Group Conference (1995)

5. S. Takubo, H. Okumura, T.Kawsaki, I.N. Abdulah, O. Uchino, et.al., Proc. of the SPIE 8526 (2012)

6. K. Arai, Proc. of the $4^{\text {th }}$ LISAT Symposium (2017) 